\title{
Comparative Study about Impact of Inadequate Psychomotor Stimulation on Neuro-Development in Pre- School Children in Rural India
}

\section{Nandita Chatterjee ${ }^{1}$ and Swati Basu ${ }^{2}$}

${ }^{1}$ Department of Paediatrics, IQ City Medical College, Durgapur, West Bengal, India

${ }^{2}$ Udbhaas Child Development Centre, Paikpara, Kolkata, West Bengal, India

\section{Correspondence: \\ Nandita Chatterjee \\ Department of Paediatrics, \\ IQ City Medical College \\ Durgapur, West Bengal, \\ India. \\ Email: chattnan@gmail.com}

DOI: $10.3126 /$ jnps.v40i2.29242

Submitted on: $2020-06-3$

Accepted on: 2020-07-3

\section{Acknowledgements: None}

Funding: Nil

Conflict of Interest: None declared

Permission from IRB: Yes

To cite this article: Chatterjee N, Basu S. Comparative study about impact of inadequate psychomotor stimulation on neuro-development in pre-school children in rural India. J Nepal Paediatr Soc. 2020;40(2):78-86.

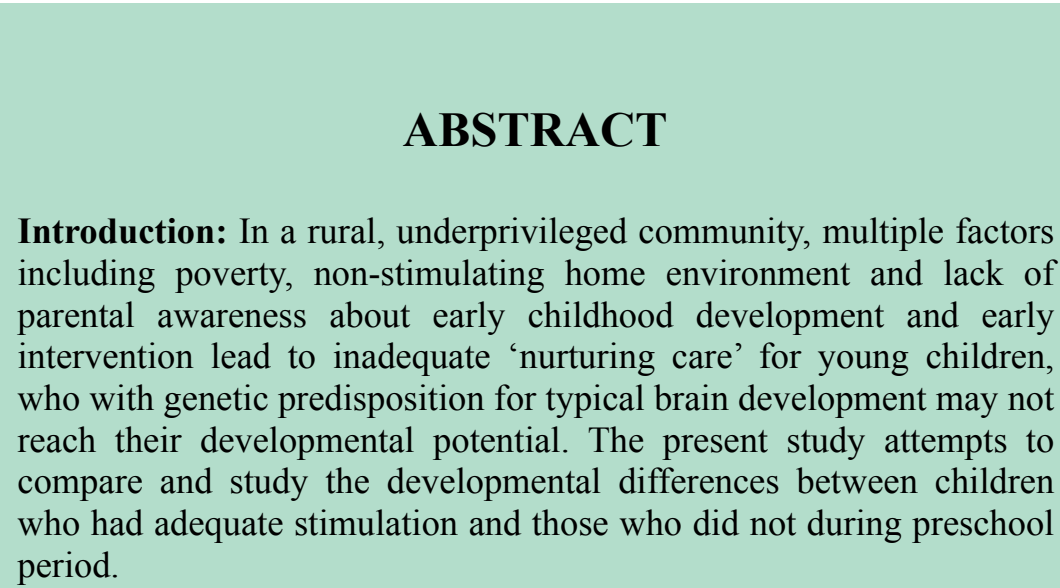

Methods: Developmental assessment of 51 healthy children, aged 3.5 - 4.5 years with poor psychomotor stimulation (study group) and an age-matched group of 27 children attending pre-school (control group) from the same community was conducted and compared. Developmental screening was done using the DDST II screening tool.

Results: The incidence of developmental delay in the study group was significantly higher; deficits were most marked in personal-social and language domain. Concept of colours, counting objects and drawing were conspicuously absent in most children.

Conclusion: Improving home environment, provision of learning opportunity with available resources, and generation of awareness among parents regarding early child development and early intervention are simple, low-cost measures to improve the developmental trajectory in these children.

Key words: early childhood development; early intervention; learning opportunity; parental awareness; psychomotor stimulation; responsive care

(CC) This work is licensed under creative common attribution 3.0 license




\section{INTRODUCTION}

A child's brain development starts from early prenatal age and continues at a prolific rate during the first three years of life. The brain comprises 100 billion neurons at birth, with each neuron developing on average 15,000 synapses by three years of age. ${ }^{1}$ This neuro-development is influenced by the child's genetic endowment and his/her environmental stimulation. Genes provide the blueprint while environment gives final shape to the brain. ${ }^{2}$ Studies have shown that heredity accounts for approximately $40 \%$ of the variance in intelligence and other personality traits like sociability; the rest is shaped by the environment. The early experiences from the environment are particularly important because learning proceeds more efficiently along established synaptic pathways. The bio-psycho-social models of development recognise the importance of both intrinsic and extrinsic forces. ${ }^{3}$ The transactional model of development (Sameroff and Chandler) ${ }^{4}$ assumes that infants, caregivers, and their environment determine the child's developmental and behavioural outcome and it is a function of the interaction between biologic and social influences. ${ }^{3,5}$

Another unique feature of development is that it proceeds from below upwards i.e., higher abilities build up on a solid platform of simpler abilities, which in turn depend on constant reciprocation the child receives from his immediate environment, which is aptly referred to as 'serve and return' mechanism. ${ }^{6}$ Contingent responses to nonverbal gestures create the groundwork for the shared attention and reciprocity critical for later language and social development. ${ }^{3}$ From this fundamental understanding of neuro-development, we may presume that children with a genetic predisposition for typical brain development may not reach his/her developmental potential due to lack of adequate psychomotor stimulation from his/her immediate environment in early in life.

To delve deeper into psychomotor stimulation, we need to focus on three aspects, i) what comprises a conducive environment in early life, ii) what stimulation is required and iii) who are the stakeholders in the immediate environment during this early period. A conducive environment must provide adequate scope for physical and mental growth in the form of healthcare, nutrition, consistent response to all his cues and responsive care, early learning facilities and protection from severe stress and neglect. 7,8 The child requires sustained and consistent attention from the caregivers right from early infancy, whereby every small cue is responded to so that the infant's brain connections develop adequately, whereby he/she masters simple abilities. Adequate exposure, appreciation and parental consistency are of prime importance in a child's development. It is needless to mention that the pivotal person in this mission is the mother. Fathers also play critical roles, both in direct relationships with the children, and in supporting mothers. The influence of other family members like grandparents, members of the greater family and non related caregivers is gaining a lot of importance in promotion of a child's development. At all stages of development children progress optimally when they have adult caregivers who pay attention to their verbal and nonverbal cues and respond accordingly.

In a rural, underprivileged society much of this 'nurturing care' is absent due to multiple factors including poverty and social deprivation as well as lack of parental awareness.

In the present study we have attempted to capture the developmental deficits, if any, in children from this under-privileged community with inadequate stimulation, compared to children from the same community who have been exposed to a rich stimulating pre-school environment.

\section{METHODS}

We selected 60 children through random sampling from three adjacent Gram Panchayats (Rural administrative regions) in an under-privileged rural community in Purulia district, West Bengal, India, aged $3.5-4.5$ years, who were otherwise healthy but did not attend any pre-school/Government run non-formal education centre (ICDS centre) regularly. Children with evident developmental delay, chronic or acute illness were excluded from the study. Facilities for psychomotor stimulation and early intervention at home were ascertained by 


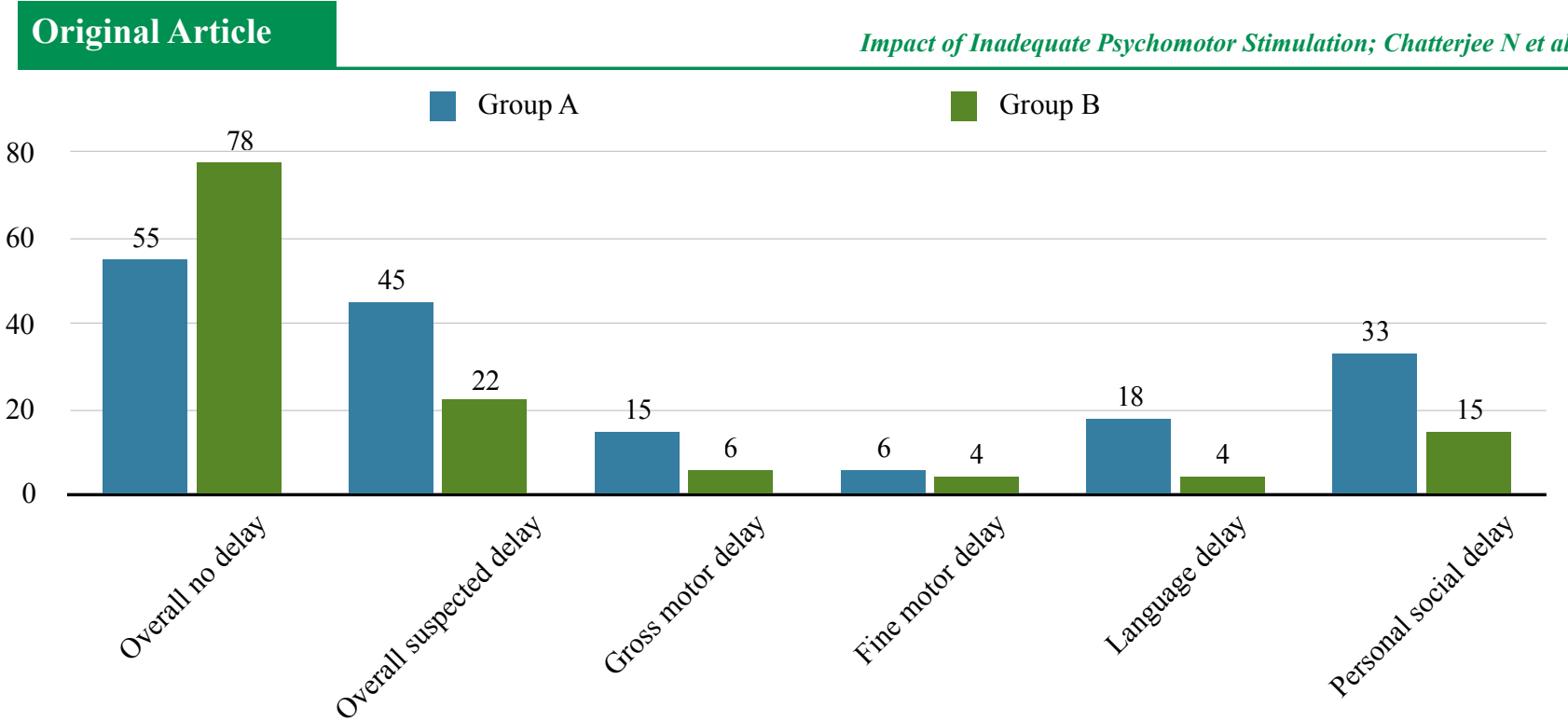

Figure 1. DDST screening compared in study group vs control group

a team of trained field level workers in all these families with a checklist of 20 items focusing on the physical environment and the parental involvement and a scoring was done. The score varied between 6 to 10 out of 40, indicating poorly stimulating learning environment at home as well as poor parental involvement in early stimulation. Of them, 51 attended the clinic for assessment. As a control group we took 27 age-matched children from a local nursery school run by a non-profit organisation. These children came from a similar socio-cultural background but had received better psychomotor stimulation at school. The study group was referred to as Group A while the control group was labeled as Group B. Developmental screening was done using the DDST II screening tool.

Table 1. Comparison of emotional factors in Groups A and $\mathrm{B}$

\begin{tabular}{|lrrr|}
$\begin{array}{l}\text { Emotional } \\
\text { factor }\end{array}$ & $\begin{array}{c}\text { Study group } \\
\mathbf{N = 5 1}(\mathbf{\%})\end{array}$ & $\begin{array}{c}\text { Control } \\
\text { group } \\
\mathbf{N}=\mathbf{2 7}(\mathbf{\%})\end{array}$ & $\begin{array}{c}\text { Significance } \\
\text { (p value) }\end{array}$ \\
\hline $\begin{array}{l}\text { Poor } \\
\text { compliance }\end{array}$ & $28(55)$ & $3(11)$ & 0.0001 \\
$\begin{array}{l}\text { Poor } \\
\text { interest }\end{array}$ & $23(45)$ & $3(11)$ & 0.002 \\
Fearfulness & $27(53)$ & $3(11)$ & 0.0001 \\
Refusal & $15(29.4)$ & $0(0)$ & 0.0001 \\
\hline
\end{tabular}

Failure/refusal to perform an activity lying to the left of the age line was considered as a failure. The total number of delays in each domain was noted and presence of two or more delays in any domain was considered as suspected delay in that domain, while a total of two delays including all four domains was considered as suspected developmental delay, as per the Denver II training manual guidelines. ${ }^{9}$

\section{RESULTS}

The home environment for psychomotor stimulation was assessed through a checklist (attached as annexure 1), where the total score out of 40 ranged between 3 to 10, with an average score of 7. Parental involvement in early childhood stimulation was lacking in most families. The results of the DDST screening test on analysis detected the number of delays or refusals in all four domains of development, from which suspected developmental delays were identified (Figure 1).

Table 2. Performance compared in few specific tests

\begin{tabular}{|lllll|}
\hline Group & $\begin{array}{l}\text { Name a } \\
\text { colour } \\
\text { Failed } \\
(\%)\end{array}$ & $\begin{array}{l}\text { Use 2 } \\
\text { objects } \\
\text { Failed } \\
(\%)\end{array}$ & $\begin{array}{l}\text { Count 1 } \\
\text { object } \\
\text { Failed } \\
(\%)\end{array}$ & Total \\
\hline A & $47(92)$ & $44(86)$ & $45(88)$ & 51 \\
\hline B** & $1(3)$ & $1(3)$ & $2(7)$ & 27 \\
\hline
\end{tabular}


Twenty three out of 51 children (45\%) in the study population had two or more delays on the DDST test, indicating suspected developmental delay. In comparison, six out of $27(22 \%)$ of the children with proper pre-school education fulfilled the criteria for 'suspected developmental delay', which was a significant difference $(\mathrm{p}=0.008)$.

Comparing the delays encountered in different domains in the two groups, we found that among the study group, number of children showing delay in gross motor, fine motor, language and personalsocial development was respectively eight $(15 \%)$, three $(6 \%)$, nine $(18 \%)$ and $17(33 \%)$. There was overlapping delay in more than one domain in some children. Personal-social development was the most affected domain. In contrast, the number of children in the control group showing delays in different domains, in the same sequence was three $(6 \%)$, one $(4 \%)$, one $(4 \%)$ and five $(15 \%)$ respectively. .

Deterrent emotional responses like fearfulness, lack of compliance, lack of interest and refusals were significantly higher in the study group than in the control (Table 1). We noticed that a good number of children in the study group were failing in a few particular age appropriate tests, which included naming a colour, counting one object and mentioning use of two objects (Table 2).

Trend of Delay in different activities:

(a) Gross motor: All the children in both groups achieved four out of six activities tested (falling on age line and three to the left), but in the last two activities requiring more skill and precision, number of delays were more in the study group, where $44 \%$ could hop and $2 \%$ could perform heel to toe walking, compared to $96 \%$ and $56 \%$ pass respectively in these activities by the control group (Figure 2)

(b) Language: Language skills were trailing behind in the study group compared to the control, showing a drastic decline in colour concept, counting and describing objects. This is depicted in the following chart showing percentage of children performing each activity (Figure 3 ).

(c) Fine motor adaptive: Fine motor skills were also less developed in the study group. Particularly drawing skills like copying a circle or square or drawing a person were developed in much less percentage among the children in group $\mathrm{A}$ compared to group B, as evident from the chart below (Figure 4).

(d) Personal Social: Personal social skills were at par in both groups up to brushing teeth with help, after which performance decreased in both groups, the study group showing a greater decline (Figure $5)$.

\section{DISCUSSION}

Early childhood development is largely dependent on environmental stimulation and lack of such stimulation at home, coupled with socio-cultural adversities prevent the child from reaching his/her developmental potential. Exposure to multiple such

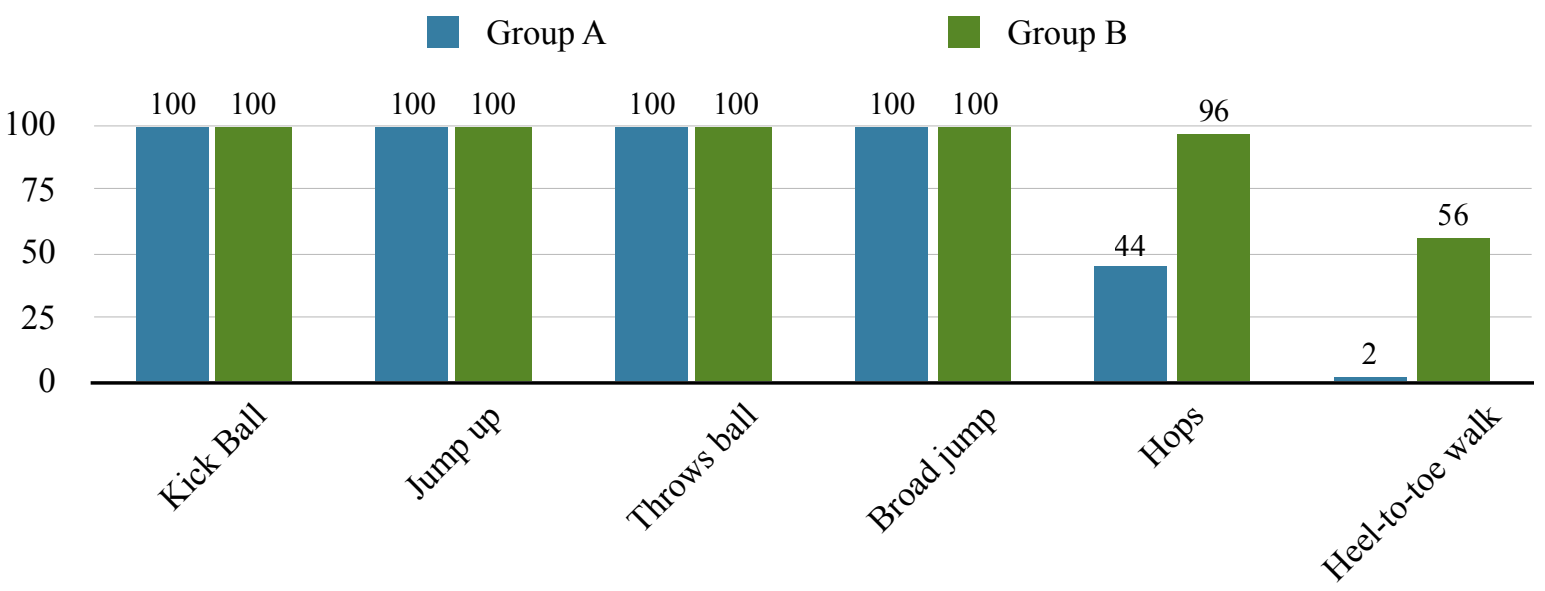

Figure 2. Gross motor 
120

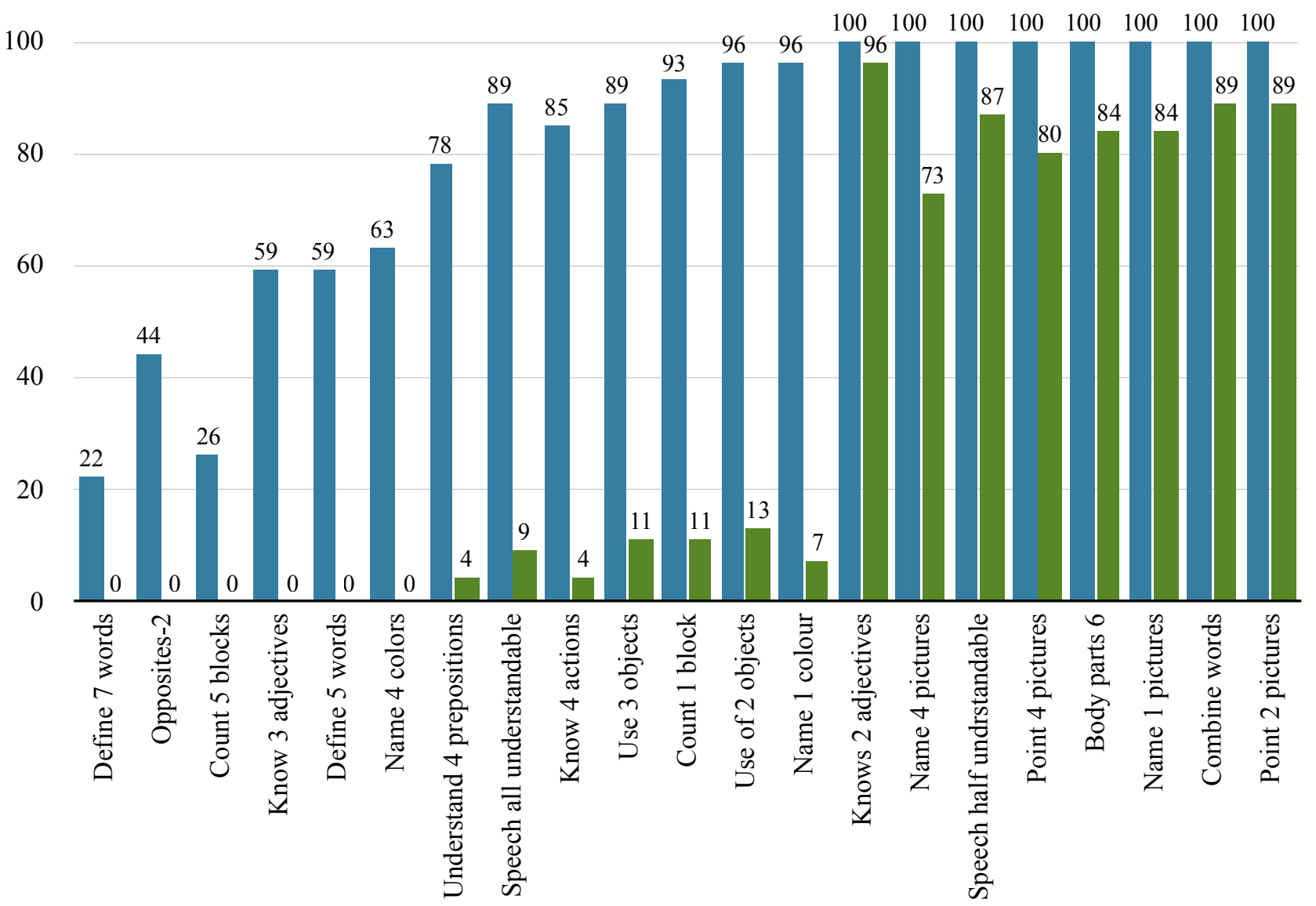

Figure 3. Gross Language

adversities is commonly met with, among the under-privileged community in low- and middleincome countries. ${ }^{10,11}$ It is estimated that 250 million children (43\%) less than five years of age in low and middle-income countries are at risk of suboptimal development. ${ }^{12}$

Studies have been conducted in different parts of the world to assess the impact of these adversities on early childhood development (ECD). A randomised controlled trial conducted in 2018 in Haryana, India, with 1,273 rural children, revealed consistent and strongly negative relationships between ECD and childhood adversities, where most children faced one or more adversity and nearly $50 \%$ faced four or more, which impeded a child's well-being. ${ }^{13}$ Developmental assessment revealed up to 8 point fall in the cognitive and 11 point fall in the language scale on BSID III. Another study by Agarwal et al. also reported associations between socio-economic status, family size with developmental scores in one to three year olds in India. ${ }^{14}$

Studies from Bangladesh by Hamadani et al. focused on socioeconomic status and home stimulation as measures of adversity and demonstrated an association with the mental developmental index. ${ }^{15}$ Other studies from Guatemala and Ecuador have described a linear relationship between cumulative psychosocial risk and cognition development. ${ }^{11,16,17}$ The various socio-economic detrimental factors which impede early childhood development have been identified as lack of opportunity for play and cognitive 
Group A

Group B

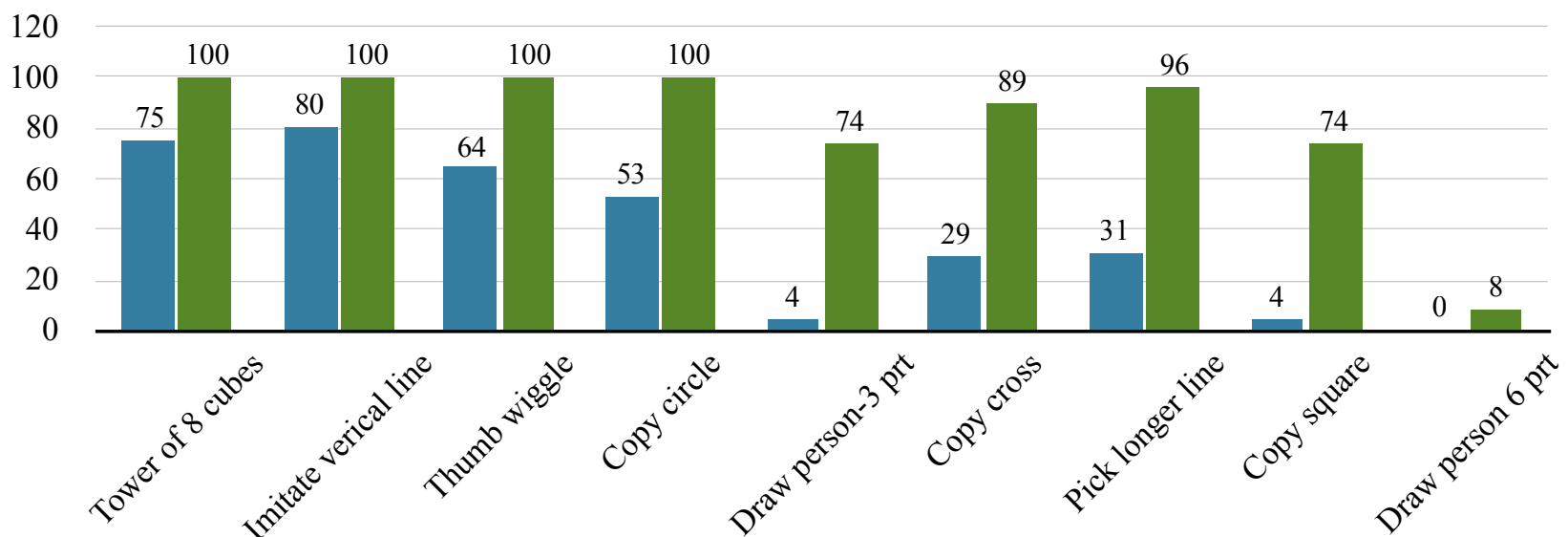

Figure 4. Fine motor

stimulation, violence at home, neglect, abuse, and parental ill-health. ${ }^{18,19}$

Various studies from across the globe have shown that poor stimulation alone can largely impede development. A study in Mexico shows that total stimulation at home was significantly associated with better performance in the gross and fine motor areas. ${ }^{20}$ An interventional study from Brazil has shown how early intervention has been associated with significant improvements in cognitive and motor development. ${ }^{21}$ In another study from
Pakistan, 1411 children were followed up till 24 months of age to demonstrate that children with responsive stimulation had significantly higher development scores on the cognitive, language, motor scales and social-emotional scale, than did those who did not receive the intervention. ${ }^{22}$

Locally available resources for a young child's psychomotor stimulation, like wall-hanging pictures, mirrors, simple toys were barely available in most houses and utilisation of these meagre resources for stimulating a child's early

\section{Group A}

Group B

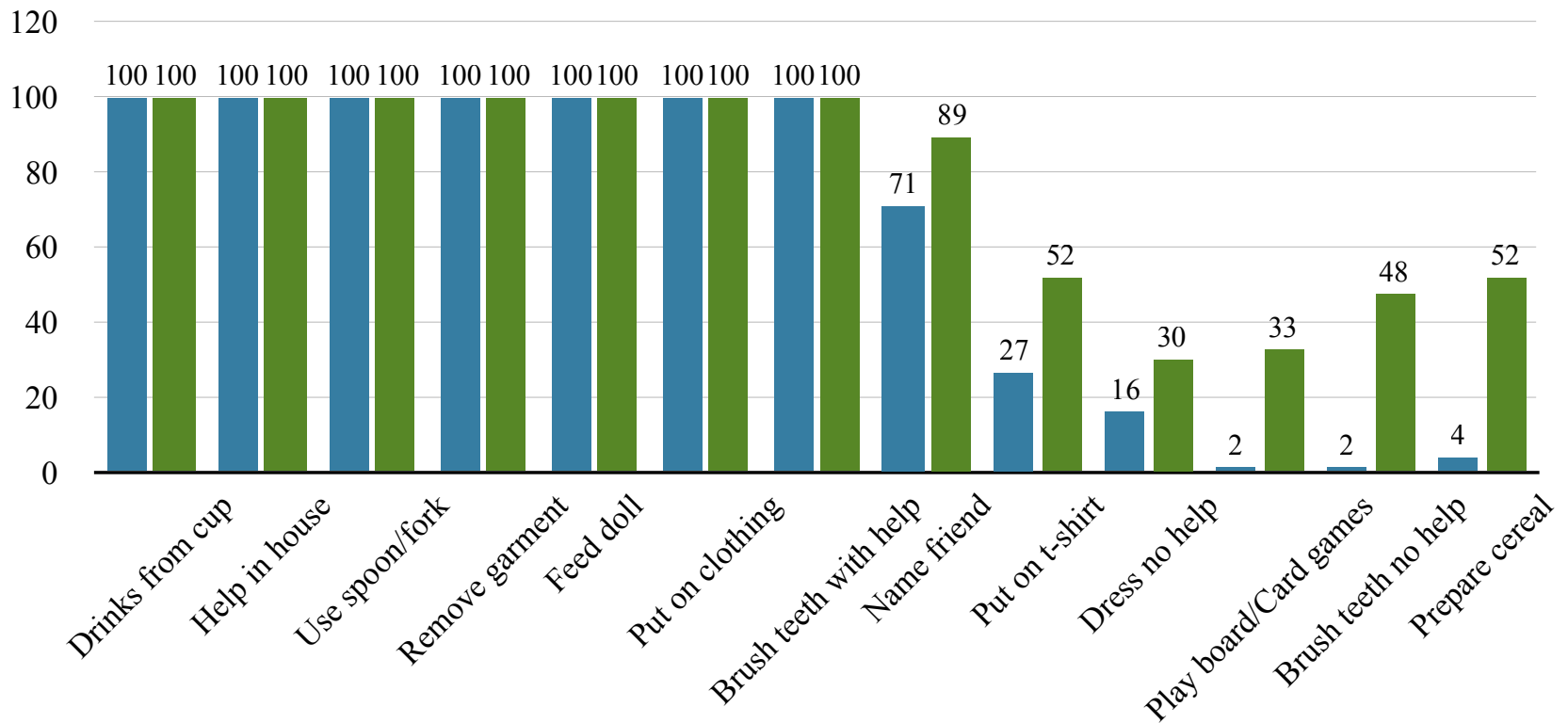

Figure 5. Personal social 
development was also missing due to lack of awareness among care-givers. Most mothers spent adequate time with their children and were eager to help them, but they lacked the knowledge and skills to provide psychomotor stimulation. Interactive play, story-telling, reading books and encouragement to scribble and draw were markedly absent. This was not only because of nonavailability but due to lack of awareness and exposure of parents. Parents and care-givers did not focus on the child's developmental milestones unless they were grossly delayed. They had no notion on how to stimulate a child's development age-wise.

The prevalent socio-cultural environmental factors among our study group, that may be conducive to ECD include peer mixing among cousins in joint families, early exposure to household chores and responsibility and having to fend for oneself from a tender age. The latter two, at a moderate level leads to mild-moderate stress, which may in turn increase resilience (Shonkoff) in the child and his/her adaptability may increase.

Coming to discipline, harsh punishments were rare, but proper positive parenting skills were also rarely practiced. Permissive parenting is most commonly practiced and child rearing practices are not a major focus area. Pre-school education and nutritional supplementation facilities are well available in the community through government run centres under the Integrated Child Development Scheme, but the facilities are under-utilised due to a communication gap between parents and providers.

The children from this socio-cultural background were showing greater incidence of developmental delay than their school-going counterparts with good stimulation. Deficits were most marked in personal-social and language domains. These children are not over-protected or pampered; they often learn to fend for themselves from early childhood. Hence motor and adaptive skills are better developed in them. Cognitive and social skills require good learning opportunity, which are lacking. This leads to deficits in communication skills and personal-social development. These children were less compliant during the tests, showed less interest and were fearful; as a result, number of refusals was significantly higher among them compared to the control group. Lack of exposure to interventions with structured activities and stranger encounter may be the underlying cause of such emotional response.

Looking closely at the individual activities tested, we noticed some remarkable features: Both groups of children showed good gross motor development till hopping, indicating a good balance and motor control. But the study group faltered with heel to toe walking, probably because they did not engage in play requiring finer motor skills like hopscotch or walking the beam. In fine motor skills the control group did better than the study group in most activities except building tower with blocks and imitating a line, which were adaptive skills, where the study group did well too. When it came to drawing a person, they did very poorly, showing a stark difference with the control group. This again was due to poor exposure to scribbling / drawing / picture books. In the personal social domain, the study group performed well in activities of daily living, i.e., personal skills, like drinking and feeding self, dressing up, helping in the house. But they faltered in the social skills like playing board games, preparing cereal etc. The greatest difference was noted in the language domain, which was largely due to lack of stimulation. The children were not exposed to basic concepts of colours or counting objects. These children had very little exposure to using colours as in drawing or referring to colours in daily life. Many of the children could recall numbers by rote memory but the concept of counting was lacking. Poor performance in language was also due to fearfulness and lack of exposure to social interaction.

So, to sum up, the children from this rural community are doing fairly well in gross motor and adaptive skills as well as activities of daily living. Their social skills are lacking and cognitive abilities are not age appropriate due to inadequate stimulation. Exposure to simple things like paperpencils, colours, picture books, counting beads etc with proper stimulation from care-givers would help them overcome this deficit and help them to achieve their best, which in the future will enable them to attain better academic and social standards. 
A low-cost investment at this stage could be the foundation for a socio-economic upliftment of the coming generation. It is felt that with simple, low cost measures like improving home environment, providing paper, pencils, colour, picture books etc, at home, utilising available Government resources and services (Integrated Child Development Centres) and above all, creating awareness among parents regarding ECD and early intervention will go a long way in improving the developmental trajectory in these children.

\section{CONCLUSIONS}

A stimulating home environment and parental engagement with child was lacking in this under privileged rural community. The children likewise were faltering in development, especially in the cognitive and language domains. Concept of colours, counting objects and drawing were conspicuously absent in most children as they had minimal exposure to learning opportunities. Exposure to a stimulating environment at the preschool, with structured learning and play activities enhanced the developmental status of the schoolgoing children from the same community. We may thus conclude that proper environment and good early learning opportunities can bring about a change in early childhood development.

\section{REFERENCES}

1. Needlman RD. Growth and development. In: Kliegman RM, Stanton BF, Schor NF, St Geme III JW and Behrman RE, 19th edition Nelsons Textbook of Pediatrics. WB Saunders, 2011; p 22-25.

2. Britto PR, Singh M, Dua T, Kaur R, Yousafzai AK. What implementation evidence matters: scaling-up nurturing interventions that promote early childhood. Ann. N.Y. Acad. Sci. 2018;1419(2018):5-16 C. PMID: 29791739 DOI: $10.1111 /$ nyas. 13720

3. GopnikA. Cognitive Development Domains and Theories. In: Kliegman RM, Stanton BF, SchorNF, St Geme III JW and Behrman RE, 20th edition Nelson Textbook of Pediatrics. Elsevier, 2016;p 54-59

4. Sameroff AJ, Chandler MJ. Reproductive risk and the continuum of caretaking causality. Rev Child Dev Res. 1974; $4: 187-244$

5. Augustyn M, Frank AF, Zuckerman BS. Infancy and toddler years. In: Carey WB, Crocker AC, Coleman WL, Elias ER, $4^{\text {th }}$ ed Developmental- behavioural Pediatrics. Elsiver Saunders, 2010.

6. Shonkoff JP. The Science of Early Childhood Development. January 2007 National Scientific Council on the Developing Child. Second Printing - November 2007. www.developingchild.net

7. Black MM, Trude ACB. Conceptualisations of child development benefit from inclusion of the nurturing care framework. J Nutr. 2019;149(8):1307-8. DOI: 10.1093/jn/nxz114

8. Britto PR, Lye SJ, Proulx K, Yousafzai AK, Matthews SG, Vaivada T, et al. Nurturing care: Promoting early childhood development. Lancet. 2017;389:91-102. DOI: 10.1016/S0140-6736(16)31390-3

9. Frankenburg WK, Dodds J, Archer P, Bresnick B, Maschka P. Denver II training manual. Denver Developmental Materials Inc. 1992;11-15.

10. Walker SP, Wachs TD, Grantham-McGregor S, Black MM, Nelson CA, Huffman SL, et al. Inequality in early childhood: risk and protective factors for early child development. Lancet. 2011;378:1325-38. DOI: 10.1016/ S0140-6736(11)60555-2

11. Wachs TD, Rahman A. The nature and impact of risk and protective influences on children's development in lowincome countries. In: Britto PR, Engle PL, Super CM, eds. Handbook of early childhood development research and its impact on global policy. Oxford: Oxford University Press, 2013:85-122. 
12. Black MM, Walker SP, Fernald LCH, Andersen CT, DiGirolamo AM, Lu C, et al. Early childhood development coming of age: science through the life course. Lancet. 2017;389(10064):77-90. DOI: 10.1016/ S0140-6736(16)31389-7

13. Bhopal S, Roy R, Verma D, Kumar D, Avan B, Khan B, et al. Impact of adversity on early childhood growth and development in rural India: Findings from the early life stress sub-study of the SPRING cluster randomised controlled trial. PLoS One. 2019;14(1):e0209122. PMID: 30625145

14. Agarwal DK, Awasthy A, Upadhyay SK, Singh P, Kumar J, Agarwal KN. Growth, behaviour, development and intelligence in rural children between 1-3 years of life. Indian Pediatr. 1992;29:467-80. PMID: 1506099

15. Hamadani JD, Tofail F, Huda SN, Alam DS, Ridout DA, Attanasio O, et al. Cognitive deficit and poverty in the first 5 years of childhood in Bangladesh. Paediatrics. 2014;134(4):1001-8. DOI: 10.1542/peds.2014-0694

16. Gorman KS, Pollitt E. Does schooling buffer the effects of early risk? Child Dev. 1996;67(2):314-26. PMID: 8625715

17. Paxson C, Schady N. Cognitive development among young children in Ecuador: The roles of wealth, health, and parenting. J Hum Resour. 2007;42:49-84.

18. Cronholm PF, Forke CM, Wade R, Bair-Merritt MH, Davis M, Harkins-Schwarz M, et al. Adverse Childhood Experiences: Expanding the Concept of Adversity. Am J Prev Med. 2015;49(3):354-61. DOI: 10.1016/j.amepre. 2015.02.001

19. Walker SP, Wachs TD, Gardner JM, Lozoff B, Wasserman GA, Pollitt E, et al. Child development: risk factors for adverse outcomes in developing countries. Lancet. 2007;369:145-57. DOI: 10.1016/S0140-6736(07)60076-2

20. Osorio E, Torres-Sánchez L, Hernández Mdel C, López-Carrillo L, Schnaas L. Stimulation at home and motor development among 36-month-old Mexican children. Salud Publica Mex. 2010;52(1):14-22. DOI:10.1590/ s0036-36342010000100004

21. Eickmann SH, Lima AC, Guerra MQ, Lima MC, Lira PI, Huttly SR, et al. Improved cognitive and motor development in a community-based intervention of psychosocial stimulation in northeast Brazil. Dev Med Child Neurol. 2003;45(8):536-41. doi: 10.1017/s0012162203000987.

22. Yousafzai AK, Rasheed MA, Rizvi A, Armstrong R, Bhutta ZA. Effect of integrated responsive stimulation and nutrition interventions in the Lady Health Worker programme in Pakistan on child development, growth, and health outcomes: A cluster-randomised factorial effectiveness trial. Lancet. 2014;384(9950):1282-93. doi:10.1016/ S0140-6736(14)60455-4 